\title{
Association of the Frequency of Respiratory IIIness in Early Childhood with a Change in the Distribution of Blood Lymphocyte Subpopulations
}

\author{
Jacob Karsh, MDCM, FRCPC; Jonathan B Angel, MD, FRCPC; \\ Charlene D Young, BSc; Vanita Sahni, MSc; Stan Judek, MSc; \\ David Miller, PhD; Robert E Dales, MD, FRCPC
}

\begin{abstract}
Little is known about the distribution of lymphocyte phenotypes in young children and the association specific phenotypes may have with respiratory illnesses. The objective of this study was to describe lymphocyte distributions in children at approximately 2 years of age and to test for associations with the frequency of respiratory illness during the first 2 years of life. We hypothesized that an increased frequency of illness would be associated with those phenotypes that reflect previous antigen exposure and/or immune activation. Seventy-three children were followed during their first 2 years of life with daily symptom diaries and twice-monthly telephone calls to ascertain the incidence of respiratory illness. After the children reached 2 years of age, the phenotypes of circulating blood lymphocytes were measured by flow cytometry. Associations between illness and phenotypes were adjusted for education level of parents; hours per week in day care; hours per week exposed to environmental tobacco smoke, mould, or water damage in bedroom; and parental history of allergy and asthma. The resulting median lymphocyte count was $4.0 \times$ $10^{9}$ per litre (standard deviation, 1.3) with a CD4/CD8 count of 2.28 , consistent with published values. Illness rates were positively associated with the percentage of CD8+CD38+T cells (unadjusted $p=.03$, adjusted $p=.014$ ), CD8+ CD45RO+ T cells (unadjusted $p=.06$, adjusted $p=.036$ ), and CD4+ CD45RO+ T cells (unadjusted $p=.01$, adjusted $p=.005$ ). Our conclusions is that there is an association between the distribution of lymphocyte phenotypes and the incidence of respiratory illness early in life. Future research is recommended to determine the directionality of this association.
\end{abstract}

T lymphocytes, identifiable by the surface expression of multiple receptors, orchestrate the immune

J. Karsh - University of Ottawa, Department of Medicine, Ottawa Hospital, Ottawa, Ontario; J. B. Angel, R. E. Dales - University of Ottawa, Ottawa Health Research Institute and Department of Medicine, Ottawa Hospital, Ottawa, Ontario; C. D. Young - Ottawa Hospital Research Institute, Ottawa, Ontario; V. Sahni, S. Judek, D. Miller Health Canada, Ottawa, Ontario

Correspondence to: Dr. Jacob Karsh, Ottawa Hospital Riverside Campus, University of Ottawa, 1967 Riverside Drive, Ottawa, ON K1H 7W9; E-mail: jkarsh@ottawahospital.on.ca system's response to antigenic stimulation. CD4 and CD8 molecules are involved in class II and class I major histocompatibility complex (MHC) interactions and participate in signal transduction following antigen recognition. Cell surface isoforms of CD45 can indicate the stage of T-cell development. The high-molecular-weight CD45RA isoform is expressed preferentially in childhood and in antigen-naive conditions; CD45RO is expressed preferentially on antigenexposed cells and increases later in life. ${ }^{1}$ Information about the expected distributions of T-cell phenotypes among young children is becoming 
available, but little is known about the relations between the distributions and rates of respiratory and other illnesses. Any relation would support clinical relevance to these distributions, whether the frequency of illness is a result of alteration of the distribution or whether the illnesses result in an alteration of the distribution. To address these issues, we measured lymphocyte distributions in children of approximately 2 years of age and tested for associations with respiratory illnesses in the first 2 years of life. We hypothesized that an increase in respiratory illnesses would be associated with an increase in those phenotypes that reflect previous antigen exposure and/or immune activation.

\section{Materials and Methods}

The present prospective study, approved by the Ethics Review Board of the Ottawa Hospital, is derived from an ongoing birth-cohort study of the influence of indoor environmental factors on respiratory illness during the first 2 years of life. The study began in 1997 and is being conducted in the province of Prince Edward Island, Canada, which has a population of approximately 150,000. All physicians who practice obstetrics in the province participated in the study. Women in the third trimester of pregnancy received letters from their physicians' offices describing the study and requesting participation. Those who expressed interest to their doctor were contacted by telephone by a member of the research team to obtain informed consent. Excluded from the study are babies born more than 4 weeks prematurely, those with neonatal respiratory difficulties requiring prolonged hospitalization at birth, and those whose families expect to change residence within 2 years of the child's birth. Because of resource constraints, we recruited approximately 40 consecutive newborns each year. Baseline socio-demographic information and family histories were obtained.

The participating parents maintained a daily symptom diary on large multipurpose calendars on which they recorded the presence or absence of symptoms of respiratory illness in the index child. For this study, four symptoms defining a respiratory-illness event were tracked daily: stuffy nose, coughing, wheezing, and shortness of breath . "Wheezing" referred to audible high-pitched musical sounds during breathing, and shortness of breath was defined by the parents' perception of rapid or laboured breathing. Each study family was phoned every 2 weeks to document information from the diary. If the parents had omitted to record symptoms on a daily basis, they provided information for that 2-week period based on recall.

We used the method of Samet to define a respiratory illness event. ${ }^{2}$ A respiratory illness event began when 2 consecutive days with at least one of the above four symptoms occurred and ended when there were 2 consecutive symptom-free days. This was done to identify discrete acute illness events as opposed to persistent ongoing symptoms such as a chronically runny nose. There were no doctors' visits, physical examinations, cultures, or blood tests to confirm an infectious event, nor did we collect information on nonrespiratory illness events. The primary outcome of interest was the number of respiratory illness events per year averaged over the 2 years of follow-up.

Lymphocyte phenotyping was performed in participating children at the age of 2 years. Peripheral blood samples were collected in a $5 \mathrm{~mL}$ Vacutainer containing ethylenediaminetetraacetic acid. One hundred microlitres of whole blood were incubated with $5 \mu \mathrm{L}$ of fluorescein isothiocyanate (FITC), phycoerythrin (PE) or phycoerythrincyanin 5.1 (PC5) anti-CD3 (UCHT1), CD4 (13B8.2), CD8 (B9.11), HLA-DR (Immu-35), CD38 (T16), CD25 (B1.49.9), CD45RA (ALB11), CD45RO (UCHL1), CD62L (DREG56) (all from Beckman Coulter, Fullerton, CA, USA), antiCD69 (L78), and CD29 (MAR4) (Pharmingen, Mississauga, ON) mABs for 25 minutes. The antibody combinations were as follows: CD3-FITC/CD4-PE/CD8-PC5, CD4-PE/HLADR-PC5/CD38-FITC, CD8-PE/HLA-DRPC5/CD38-FITC, CD4-PE/CD25-PC5/CD69FITC, CD8-PE/CD25-PC5/CD69-FITC, CD 4 - PC 5 / CD 45 R A - P / CD 62 L - FI T C, CD8-PC5/CD45RA-P/CD62L-FITC, CD4PC5/CD45RO-FITC/CD29-PE, and CD8PC5/CD45RO-FITC/CD29-PE. Autofluorescence and colour compensation tubes were also included. 
The samples were then lysed with the ImmunoPrep reagent system on a Coulter Multi-Q-Prep workstation. Ten thousand lymphocytes were acquired on a Beckman Coulter EPICS ALTRA flow cytometer, and the data was analyzed with EXPO2 analysis software. Lymphocyte subsets were distinguished from nonlymphoid cells by light scattering profiles, ${ }^{3}$ and the expression of the various cell surface molecules was determined on $\mathrm{CD}^{+}$and $\mathrm{CD} 8^{+} \mathrm{T}$ cells.

The illness rate per year was correlated with clinical data, and the percentage of lymphocytes expressing one or more cell surface antigens was measured at age 2 years with Pearson's correlation coefficient. Results were then adjusted for any characteristics that were either associated with the incidence of illness or the lymphocyte subpopulation distributions. Multivariate analysis was not performed, and because this was an exploratory study, $p$ values were not corrected for the multiple comparisons.

\section{Results}

The parents of 73 children volunteered their children to provide blood. The children were relatively evenly divided in regard to sex (Table 1). Approximately one-half had at least one parent with a history of allergy, asthma, or both. The majority had a sibling, and most had been cared for outside the home. The median number of illness events per year per child was 7.4 (range, 1.5-13.6), which was identical to the mean number of illness events per year $(7.4 \pm 2.6$ [standard deviation]). This suggested that the data were normally distributed.

The phenotypic characteristics of the lymphocyte subpopulations are presented in Table 2 . The median lymphocyte count was $4.0 \times 10^{9}$ per litre (standard deviation [SD], 1.3), and the CD4/CD8 ratio was 2.28 , consistent with the published values for children of this age. ${ }^{4-6}$ The majority of lymphocytes expressed the immature or antigen-naive $\mathrm{CD} 45$ isoform: $17 \%$ were $\mathrm{CD} 4^{+}$ $\mathrm{CD}^{2} 5 \mathrm{RO}^{+}$whereas $82 \%$ were $\mathrm{CD} 4{ }^{+} \mathrm{CD} 45 \mathrm{RA}^{+}$, and $13 \%$ were $\mathrm{CD}^{+} \mathrm{CD}^{+} 4 \mathrm{RO}^{+}$whereas $89 \%$ were $\mathrm{CD} 8 / \mathrm{CD} 45 \mathrm{RA}^{+}$.

Associations were tested between illness rates and phenotypes, unadjusted and then adjusted by multivariate regression for variables that were associated with either the phenotype or illness rate. ${ }^{7,8}$ These variables were education level of parents; hours per week in day care; hours per week exposed to environmental tobacco smoke, mould, or water damage in the bedroom; and parental history of allergy and asthma. Illness rates were positively associated with the percentage of $\mathrm{CD}^{+}$ $\mathrm{CD}^{2} 8^{+} \mathrm{T}$ cells (unadjusted $p=.03$, adjusted $p=.014), \mathrm{CD}^{+} \mathrm{CD}^{+} 5 \mathrm{RO}^{+} \mathrm{T}$ cells (unadjusted $p=.06$, adjusted $p=.036$ ), and $\mathrm{CD}^{+}{ }^{+} \mathrm{CD} 45 \mathrm{RO}^{+}$ T cells (unadjusted $p=.01$, adjusted $p=.005$ ) (Table 3).

\section{Discussion}

With a greater appreciation of the significance of various lymphocyte subpopulations and the availability of monoclonal antibodies to identify dis-

Table 1 Characteristics of Children in Study

\begin{tabular}{lll}
\hline Characteristic & $N$ & $\%$ \\
\hline Female & 73 & 45 \\
Has sibling(s) & 73 & 66 \\
One parent has some university education & 73 & 56 \\
Family income < \$50,000 (Canadian) per year & 72 & 51 \\
Parental history of asthma or allergies & 72 & 56 \\
Ever cared for outside home & 73 & 81 \\
Exposed to environmental tobacco smoke $>0.5 \mathrm{~h} / \mathrm{wk}$ & 73 & 41 \\
\hline
\end{tabular}

$\mathrm{wk}=$ week. 
Table 2 Characteristics of Lymphocytes

\begin{tabular}{|c|c|c|c|c|}
\hline Lymphocyte & No. of Subjects & Mean & Median & SD \\
\hline \multicolumn{5}{|c|}{ (\% indicates proportion of cells with that marker) } \\
\hline Total lymphocytes & 67 & 4.04 & 3.9 & 1.34 \\
\hline$\% \mathrm{CD} 3 / \mathrm{CD}^{+*} *$ & 73 & 64.41 & 65.9 & 8.19 \\
\hline$\% \mathrm{CD} 3 / \mathrm{CD}^{+}$ & 71 & 29.61 & 28.9 & 8.56 \\
\hline$\% \mathrm{CD} 4 / \mathrm{CD} 38^{+\dagger}$ & 73 & 85.55 & 87.9 & 7.88 \\
\hline$\% \mathrm{CD} 4 / \mathrm{HLA}-\mathrm{DR}^{+}$ & 71 & 4.48 & 4.5 & 2.08 \\
\hline$\% \mathrm{CD} 4 / \mathrm{CD} 38^{+} / \mathrm{HLA}^{-\mathrm{DR}^{+}}$ & 71 & 2.83 & 2.6 & 1.29 \\
\hline$\% \mathrm{CD} 8 / \mathrm{CD} 38^{+}$ & 73 & 73.88 & 76.8 & 11.94 \\
\hline$\%$ CD8/HLA-DR ${ }^{+}$ & 71 & 7.96 & 6.2 & 6.91 \\
\hline$\% \mathrm{CD} 8 / \mathrm{CD} 38^{+} / \mathrm{HLA}^{-\mathrm{DR}^{+}}$ & 70 & 6.42 & 4.515 & 6.82 \\
\hline$\% \mathrm{CD} 4 / \mathrm{CD} 25^{+}$ & 73 & 5.56 & 5.8 & 2.84 \\
\hline$\% \mathrm{CD} 4 / \mathrm{CD} 9^{+}$ & 73 & 1.11 & 0.8 & 1.52 \\
\hline$\% \mathrm{CD} 8 / \mathrm{CD} 25^{+}$ & 73 & 1.07 & 0.7 & 1.83 \\
\hline$\% \mathrm{CD} 8 / \mathrm{CD} 9^{+}$ & 73 & 2.03 & 1.7 & 2.03 \\
\hline$\% \mathrm{CD} 4 / \mathrm{CD} 45 \mathrm{RA}^{+}$ & 73 & 81.60 & 82.1 & 6.10 \\
\hline$\% \mathrm{CD} 4 / \mathrm{CD} 45 \mathrm{RA}^{+} / \mathrm{CD}^{2} \mathrm{~L}^{+}$ & 72 & 77.93 & 78.65 & 7.52 \\
\hline$\% \mathrm{CD} 8 / \mathrm{CD} 45 \mathrm{RA}^{+}$ & 73 & 89.56 & 91.3 & 7.36 \\
\hline$\% \mathrm{CD} 8 / \mathrm{CD} 45 \mathrm{RA}^{+} / \mathrm{CD}^{2} \mathrm{~L}^{+}$ & 72 & 70.79 & 71.5 & 11.53 \\
\hline$\% \mathrm{CD} 4 / \mathrm{CD} 45 \mathrm{RO}^{+}$ & 72 & 17.04 & 14.8 & 13.80 \\
\hline$\% \mathrm{CD} 8 / \mathrm{CD}_{4} 5 \mathrm{RO}^{+}$ & 72 & 13.07 & 8.40 & 13.65 \\
\hline$\% \mathrm{CD} 4 / \mathrm{CD} 29^{+}$ & 70 & 88.54 & 90.95 & 9.04 \\
\hline$\% \mathrm{CD} 8 / \mathrm{CD} 29^{+}$ & 72 & 86.38 & 88.55 & 8.52 \\
\hline
\end{tabular}

$\mathrm{SD}=$ standard deviation

*Values represent percentage of CD3 lymphocytes that express CD4 or CD8.

$\dagger$ Values represent percentage of $\mathrm{CD} 3+\mathrm{CD} 4+$ or $\mathrm{CD} 3+\mathrm{CD} 8+$ cells that express additional cell surface markers.

tinct subsets, characterizing the distribution of subsets and how they are affected by age has to be the subject of a limited number of studies. The most thorough study was recently published by Shearer and colleagues, who evaluated lymphocyte subsets in a cross-sectional study of 807 healthy children from birth to 18 years of age. ${ }^{6}$ Their findings, which are consistent with ours and those of others, ${ }^{9,10}$ were that compared to adolescents and adults, ${ }^{6,11}$ children have a relatively larger proportion of $\mathrm{CD}^{+} \mathrm{T}$ cells expressing CD45RA or both CD45RA and CD62L, indicating that the majority of circulating $\mathrm{T}$ cells are antigen naïve. 1 Interestingly, the children we studied also had a greater proportion of both $\mathrm{CD}^{+}$and $\mathrm{CD}^{+} \mathrm{T}$ cells that expressed CD38 (typically considered a marker of immune activation) as compared to adults, ${ }^{11}$ which is also consistent with the observations of others. ${ }^{6,12}$ Whether this is an age-related phenomenon and whether there are specific environmental factors that explain this finding remain to be established.
Within our population of healthy children, a higher rate of upper respiratory illness events was associated with a higher percentage of activated $\mathrm{T}$ cells as indicated by coexpression of CD38 or HLA-CD45RO. We concede that despite being statistically significant, the $r$ values are low, suggesting that the event rates contributed only a small part to the lymphocyte profiles. Our definition of a respiratory event is based on parents' observations of very young children, and we presume that the events are infectious; however, we did no studies to confirm this. Further, because we did not collect information on nonrespiratory illness events, we were unable to assess how this might have affected the distribution of lymphocytes at age 2 years and the magnitude of the correlation coefficients. Although the alterations in the lymphocyte distributions may be the cause of the increase in illness rates, the increase in the activation markers $(\mathrm{CD} 38, \mathrm{RO})$ reflect antigen exposure and therefore makes it more likely that the respiratory events influenced the distribution of $\mathrm{T}$ cells. 
Table 3 Association between Lymphocytes and Illness

\begin{tabular}{|c|c|c|c|c|c|}
\hline \multirow[b]{2}{*}{ Lymphocyte } & \multirow[b]{2}{*}{ Correlation (r) } & \multicolumn{2}{|c|}{ Unadjusted Estimate* } & \multicolumn{2}{|c|}{ Adjusted Estimate $^{\dagger}$} \\
\hline & & Effect (B) & $p$ Value & Effect (B) & $p$ Value \\
\hline \multicolumn{6}{|c|}{ (\% indicates proportion of cells with that marker) } \\
\hline Total lymphocytes & -0.06367 & -0.00230 & 0.6087 & -0.00583 & 0.2149 \\
\hline$\% \mathrm{CD} 3 / \mathrm{CD}^{+}{ }^{+}$ & -0.18932 & -0.03977 & 0.1087 & -0.02070 & 0.4068 \\
\hline$\% \mathrm{CD} 3 / \mathrm{CD}^{+}$ & 0.23017 & 0.05067 & 0.0535 & 0.03720 & 0.1588 \\
\hline$\% \mathrm{CD} 4 / \mathrm{CD} 38^{+}$ & $0.17652 \mathrm{~s}$ & 0.03567 & 0.1352 & 0.04918 & 0.0510 \\
\hline$\%$ CD4/HLA-DR ${ }^{+}$ & 0.16187 & 0.00861 & 0.1774 & 0.00830 & 0.2412 \\
\hline$\%$ CD4/CD38+/HLA-DR ${ }^{+}$ & 0.0333 & 0.00111 & 0.7824 & -0.00135 & 0.7566 \\
\hline$\% \mathrm{CD} 8 / \mathrm{CD} 38^{+}$ & 0.26042 & 0.07976 & 0.0261 & 0.09751 & 0.0136 \\
\hline$\%$ CD8/HLA-DR ${ }^{+}$ & 0.09073 & 0.01598 & 0.4518 & 0.00493 & 0.8263 \\
\hline$\%$ CD8/CD38+/HLA-DR ${ }^{+}$ & 0.09125 & 0.01585 & 0.4525 & 0.00336 & 0.8780 \\
\hline$\% \mathrm{CD} 4 / \mathrm{CD} 25^{+}$ & -0.03003 & -0.00219 & 0.8009 & -0.00049135 & 0.9575 \\
\hline$\%$ CD4/CD69 ${ }^{+}$ & 0.1319 & 0.00517 & 0.2659 & 0.00643 & 0.1958 \\
\hline$\% \mathrm{CD} 8 / \mathrm{CD} 25^{+}$ & -0.01634 & -0.00076856 & 0.8908 & 0.00186 & 0.7562 \\
\hline$\% \mathrm{CD} 8 / \mathrm{CD} 69^{+}$ & 0.10676 & 0.00310 & 0.3687 & 0.00393 & 0.2955 \\
\hline$\% \mathrm{CD} / \mathrm{CD} 45 \mathrm{RA}^{+}$ & -0.01446 & -0.00226 & 0.9034 & -0.00554 & 0.7711 \\
\hline$\% \mathrm{CD} 4 / \mathrm{CD} 45 \mathrm{RA}^{+} / \mathrm{CD} 6 \mathrm{~L}^{+}$ & +-0.00767 & -0.00148 & 0.9490 & -0.00364 & 0.8789 \\
\hline$\% \mathrm{CD} 8 / \mathrm{CD} 45 \mathrm{RA}^{+}$ & 0.0289 & 0.00546 & 0.8082 & 0.02100 & 0.3590 \\
\hline$\% \mathrm{CD} 8 / \mathrm{CD} 45 \mathrm{RA}^{+} / \mathrm{CD} 6 \mathrm{~L}^{+}$ & 0.01099 & 0.00325 & 0.9270 & 0.02944 & 0.4032 \\
\hline$\% \mathrm{CD} 4 / \mathrm{CD} 45 \mathrm{RO}^{+}$ & 0.30264 & 0.10651 & 0.0098 & 0.13033 & 0.0048 \\
\hline$\% \mathrm{CD} 8 / \mathrm{CD} 45 \mathrm{RO}^{+}$ & 0.21943 & 0.07640 & 0.0640 & 0.09587 & 0.0359 \\
\hline$\% \mathrm{CD} 4 / \mathrm{CD} 29^{+}$ & 0.02811 & 0.00644 & 0.8173 & 0.01390 & 0.5441 \\
\hline$\% \mathrm{CD} 8 / \mathrm{CD} 29^{+}$ & 0.0559 & 0.01215 & 0.6408 & 0.01344 & 0.6391 \\
\hline
\end{tabular}

*Lymphocyte $=$ illness (note: $\mathrm{B}$ value is that corresponding to illness).

'Lymphocyte $=$ illness + parents with university education + hours/week cared for outside home + hours/week of environmental tobacco smoke + ever water damage or mould in bedroom + parental history of asthma or allergy.

Our major observation was an increased percentage of activated CD8 cells expressing CD38 or CD45RO in those children who had a greater frequency of respiratory events. In an earlier study, we demonstrated that residential fungal exposure altered the biologic host response as measured by an increase in the percentage of total lymphocytes expressing CD45RO and CD29. ${ }^{1}$ We have no evidence that the alteration in the distribution of T-cell subsets in children is associated with an alteration in lymphocyte function.

However, the possible consequence of increased microbial challenge early in life has been summarized in the "hygiene" hypothesis, ${ }^{13,14}$ which proposes that lack of microbial challenge early in life promotes the later development of atopic diseases, such as hay fever and asthma, and diminishes the later expression of autoimmune diseases such as rheumatoid arthritis. How this occurs is not known. One proposed mechanism is an alteration in the balance between mutually antagonistic subsets of CD4-positive helper $\mathrm{T}$ cells in favour of the $\mathrm{T}$ helper 2 (Th2) response mediating allergic responses and against the Th1 response mediating autoimmune disease. Nevertheless, the results of three large population-based studies argue against this interpretation by finding concomitant increases in both Th1-mediated autoimmune diseases and Th2-mediated allergic diseases. ${ }^{15-17}$ Bach proposed that a loss of regulatory function may explain the mechanism of the hygiene hypothesis. ${ }^{18}$ Humans and animals with autoimmune and atopic diseases are noted for deficient T-suppressor cell function. ${ }^{19}$ A property of activated CD8 lymphocytes is regulation (suppression) of immune responses. ${ }^{13,18,20}$ In mice, Tregulatory cells express CD8 and HLA-DR (MHC II) 19 and can suppress CD4-mediated autoim- 
munity. ${ }^{21-23}$ According to this interpretation of the hygiene hypothesis, microbial challenge will enhance suppressor function and diminish the later development of all categories of immunemediated (hypersensitivity) diseases. However, whether human $\mathrm{CD} 8^{+} \mathrm{T}$ cells expressing $\mathrm{CD} 38$ or $\mathrm{CD} 45 \mathrm{RO}$ have a regulatory (suppressor) function remains to be established.

We have described characteristics of peripheral lymphocytes in a group of 2-year-old children. In this study and in an earlier study, ${ }_{1}^{1}$ we believe we have demonstrated that antigen exposure results in a change in immunophenotype from a naive to activated memory status and that the exact changes vary depending on the stimulus, such as fungal exposure (as in the earlier study) ${ }^{1}$ and viruses (as in this study). However, much further research is recommended, to confirm the directionality of the associations, the effects in repertoire (distribution of lymphocytes) by single and repeated exposures, and the functions of the lymphocyte subpopulations in question. Much more information is needed prior to embarking on population health planning directed at influencing the distribution of circulating lymphocytes at a young age in order to influence susceptibility to diseases at a later age.

\section{Acknowledgments}

This work was supported by Health Canada, the Canada Mortgage and Housing Corporation, the Prince Edward Island Reproductive Care Program, the Prince Edward Island Medical Society, Carleton University, and the Prince Edward Island Department of Health and Social Services. The authors dedicate this article to Dr. A. I. Lazarovits, who passed away when far too young.

\section{References}

1. Dales R, Miller D, White J, et al. Influence of residential fungal contamination on peripheral blood lymphocyte populations in children. Arch Environ Health 1998;53:190-5.

2. Samet J. Nitrogen dioxide and respiratory illness in children. Part 1: Health outcomes. Health Effects Institute, Ottawa, Ontario; 1993. Research Report No.: 58.
3. Hoffman RA, Kung PC, Hansen WP, Goldstein G. Simple and rapid measurement of human Tlymphocytes and their subclasses in peripheral blood. Proc Natl Acad Sci 1980;77:4914-7.

4. Denny T, Yogev R, Gelman R, et al. Lymphocyte subsets in healthy children during the first 5 years of life. JAMA 1992;267:1484-88.

5. Falcao RP, Ismael SJ, Donadi EA. Age associated changes of T lymphocyte subsets. Diagn Clin Immunol 1987;5:205-8.

6. Shearer WT, Rosenblatt HM, Gelman RS, et al. Lymphocyte subsets in healthy children through 18 years of age: The Pediatric AIDS Clinical Trials Group P1009 study. J Allergy Clin Immunol 2003;112:973-80.

7. Marbury MC, Maldonado G, Waller L. Lower respiratory illness, recurrent wheezing, and day care attendance. Am J Respir Crit Care Med 1997;155:156-61.

8. Nafstad P, Hagen JA, Oie L, et al. Day care centers and respiratory health. Pediatrics 1999;103:753-8.

9. Katevas P, Lembesopoulos C, Kamitaki C, et al. Establishment of normal ranges of lymphocyte subpopulations in cord blood and in peripheral blood in infants and in children. J Hellenic Soc Hematol 1999;2:145-51.

10. Ikinciogullari A, Kendirli T, Dogu F, et al. Peripheral blood lymphocyte subsets in healthy Turkish children. Turk J Pediatr 2004;46:125-30.

11. Bisset LR, Lung TL, Kealin M, et al. Reference values for peripheral blood lymphocyte phenotypes applicable to the healthy adult population in Switzerland. Eur J Haematol 2004;72:203-12.

12. McCloskey TW, Cavaliere T, Bakshi S, et al. Immunophenotyping of T lymphocytes by threecolor flow cytometry in healthy newborns, children and adults. Clin Immunol Immunopathol 1997;84:46-55.

13. Bach JF. The effect of infections on susceptibility to autoimmune and allergic diseases. $\mathrm{N}$ Engl J Med 2002;347:911-20.

14. Strachan DP. Hay fever, hygiene, and household size. BMJ 1989;299:1259-60.

15. Kero J, Gissler M, Hemminki E, Isolauri E. Could TH1 and TH2 diseases co-exist? Evaluation of asthma incidence in children with coeliac disease, type 1 diabetes, or rheumatoid arthritis: a register study. J Allergy Clin Immunol 2001;108:781-3. 
16. Simpson CR, Anderson WJA, Helms PJ, et al. Coincidence of immune-mediated diseases driven by $\mathrm{TH} 1$ and $\mathrm{TH} 2$ subsets suggests a common aetiology: a population-based study using computerized general practice data. Clin Exp Allergy 2002;32:37-42.

17. Sheikh A, Smeeth L, Hubbard R. There is no evidence of an inverse relationship between TH2-mediated atopy and TH1-mediated autoimmune disorders: lack of support for the hygiene hypothesis. J Allergy Clin Immunol 2003;111:131-5.

18. Bach JF. Autoimmune diseases as the loss of active "self-control." Ann N Y Acad Sci 2003;998:161-77.

19. Mason D, Fowell D. T-cell subsets in autoimmunity. Curr Opin Immunol 1992;4:728-32.
20. Filaci G, Suciu-Foca N. CD8+ T suppressor cells are back to the game: are they players in autoimmunity? Autoimmun Rev 2002;1:279-83.

21. Field AC, Caccavelli L, Bloch MF, Bellon B. Regulatory CD8+ T cells control neonatal tolerance to a Th2-mediated autoimmunity. J Immunol 2003;170:2508-15.

22. Cortesini R, LeMaoult J, Ciubotariu R, Cortesini NS. CD8+CD28-T suppressor cells and the induction of antigen-specific, antigen-presenting cell-mediated suppression of Th reactivity. Immunol Rev 2001;182:201-6.

23. Koh DR, Fung-Leung WP, Ho A, et al. Less mortality but more relapse in experimental allergic encephalomyelitis in CD8-/- mice. Science 1992;256:1210-3. 